\title{
Diode Laser as an Adjuvant in Treating Endo-perio Lesions in Maxillary Incisors
}

\author{
${ }^{1}$ Arulmozhi Nandakumar, ${ }^{2}$ Sudhagar Ganesan, ${ }^{3} \mathrm{~S}$ Shalini
}

\begin{abstract}
The application of laser in endodontic therapy has been extensively studied. In few cases both periodontal and pulpal disease present simultaneously and pose a significant challenge in diagnosis, treatment planning, as well as healing of the endoperio lesion. This study aims at orderly treating endo-perio lesions with the help of diode laser. The case reports deal with true endodontic and combined endo-perio lesion in maxillary incisors. True endodontic lesion in 11 was treated with root canal obturation after disinfection with diode laser. Combined endo-perio lesion in 21 was treated with root canal obturation assisted by diode disinfection, scaling, and laser curettage and cleaning of periodontal pocket. The procedure resulted in resolution of periodontal pocket depth after 2 months. One year review of both cases showed healing of periapical lesion and maintenance of periodontal health. Diode laser is an excellent tool in handling soft tissues, gingiva, and periodontium due to less tissue shrinkage, less intraoperative time, and reduced postoperative discomfort. Laser disinfection of root canals assists in healing and prognosis in complicated situations. The use of lasers may lead to developing better and predictable treatment protocol for endodontic periodontal lesions.
\end{abstract}

Keywords: Dental laser, Endo-perio lesion, Laser assisted new attachment procedure, Root canal disinfection.

How to cite this article: Nandakumar A, Ganesan S, Shalini S. Diode Laser as an Adjuvant in Treating Endo-perio Lesions in Maxillary Incisors. Int J Laser Dent 2015;5(3):68-73.

Source of support: The team extends its sincere thanks to Dr Dhipak Arthur for his help with photography and our dental assistants, whose support played a pivotal part of our study.

Conflict of interest: None

\section{INTRODUCTION}

The application of laser in endodontic therapy has been extensively studied in adults, and it provides promising

\footnotetext{
${ }^{1}$ Dentist, ${ }^{2,3}$ General Practitioner

${ }^{1}$ Department of Laser Dentistry, Manipal College of Dental Sciences, Chennai, Tamil Nadu, India

${ }^{2}$ Department of General Dentistry, JKK Nataraja Dental College Chennai, Tamil Nadu, India

${ }^{3}$ Department of General Dentistry, Rajah Muthiah Dental College and Hospital, Vellore, Tamil Nadu, India
}

Corresponding Author: Arulmozhi Nandakumar, Dentist Department of Laser Dentistry, Manipal College of Dental Sciences, Chennai, Tamil Nadu, India, Phone: +919003273438 e-mail: docarulmozhi@gmail.com treatment modality in both pediatric and adolescent age groups. The objective of endodontic treatment lies in eliminating bacteria from the root canal, preserving and restoring the health of periapical tissue and surrounding periodontium. Laser-assisted endodontic treatment is indicated for teeth with periapical lesion, pulpal necrosis, periapical abscess, and lateral canals with periodontal involvement. ${ }^{1}$ When pulp becomes inflamed due to noxious stimuli, it causes secondary inflammatory changes in the apical and lateral periodontal tissue. ${ }^{2}$ The acute exacerbation of chronic apical disease drains through the gingival sulcus and mimics periodontal abscess. In such cases, endodontic treatment alone leads to resolution of symptoms in the periodontium. On the contrary, in few cases both periodontal and pulpal disease present simultaneously and the condition is termed as "Endo-Perio" lesion, which was first described in 1964 by Simring and Goldberg. ${ }^{3}$ Careful diagnosis co-relating the patient's history, clinical signs, and diagnostic test establishes the origin of the disease, and prognosis is mainly governed by the extent of the presenting periodontal involvement. ${ }^{4}$

Lasers have evolved to have varied application in the field of dentistry, especially endodontics. Diode lasers are majorly soft-tissue surgical lasers ranging from wavelengths of 810 to $980 \mathrm{~nm}$, which cut tissue in the contact mode. The $810 \mathrm{~nm}$ wavelength has favorable absorption in the pulpal tissue; hence precise and selective pulp removal is possible without affecting the surrounding dentin and enamel as they are not absorbed in hard tissue. ${ }^{5}$ Hence diode lasers with judicious handling do not cause much collateral damage.

\section{SELECTION CRITERIA}

- Nonvital teeth with pulpal necrosis for prolonged duration

- Teeth with periapical pathology, like abscess or chronic apical periodontitis

- Teeth with lateral canals and periodontal involvement.

\section{CASE REPORTS}

\section{Case 1}

A 20-year-old female reported to our dental hospital, with chief complaint of pain from the broken upper 
front tooth; she developed swelling adjacent to the tooth for the past 1 month. She presented with a history of fall and subsequent fracture of upper central incisor 11 (FDI system) 7 years ago and subsequent discoloration of the tooth. No intervention was done for past 7 years, owing to lack of knowledge of the parents and absence of any symptoms or signs except for discoloration of the tooth. On clinical examination, nonvital 11 presented with fracture involving the pulp and soft fluctuant abscess in the muccobuccal fold in relation to 11 (Fig. 1). Thermal pulp test showed negative for both 11 and 12 . Intraoral periapical (IOPA) radiograph revealed large, well-demarcated periapical radiolucency involving both 11 and 12 and apical periodontal widening (Fig. 2). The diagnosis of chronic apical periodontitis was arrived for 11,12 . Hence root canal therapy was advised for both 11 and 12 along with drainage of the abscess with the help of $810 \mathrm{~nm}$ diode laser (Picasso, AMD Laser).

After obtaining consent from the parent, local anesthesia of $1.5 \mathrm{~mL}$ was buccally infiltrated in relation to 11, 12. All laser precautions were ensured and using a

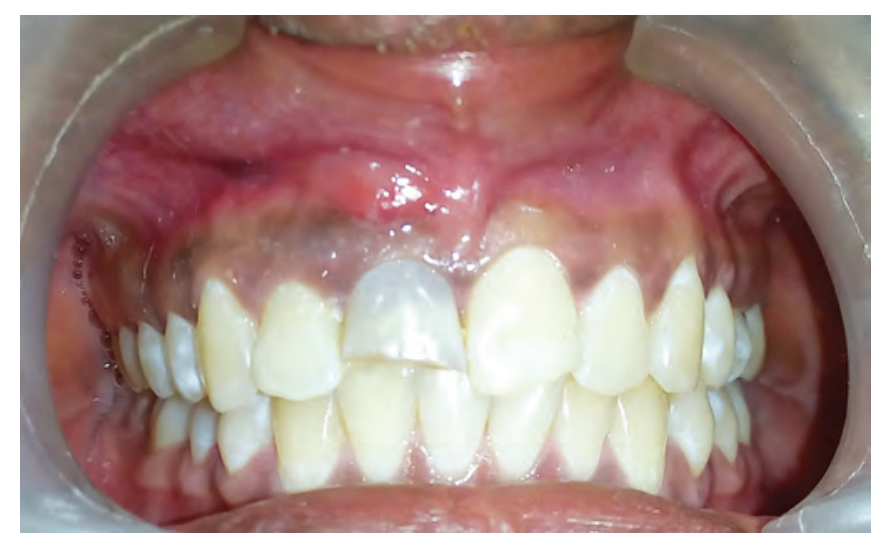

Fig. 1: Preoperative photograph of nonvital 11, 12 with swelling in relation to periapical region of 11

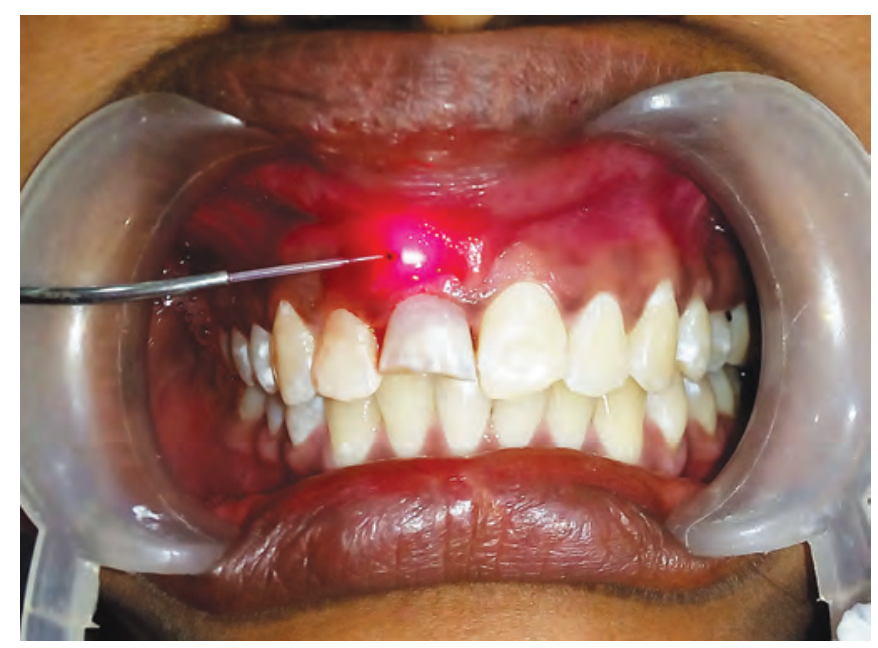

Fig. 3: Drainage of periapical abscess with diode laser
$400 \mu \mathrm{m}$ initiated tip in contact mode and $1 \mathrm{~W}$ power, the abscess in relation to 11 was incised with firm repeated strokes till it drained buccally (Fig. 3). Following which low-level laser therapy was done in defocused mode over the buccal mucosa. Under adequate aseptic conditions, the access cavity was prepared in 11, 12 after recording the working length; biomechanical preparation was done with 3\% sodium hypochlorite and saline irrigation; a $400 \mu \mathrm{m}$ noninitiated tip was introduced in circular motion from cervical to apical portion of the canal $2 \mathrm{~mm}$ at a time; laser disinfection was limited to $1 \mathrm{~mm}$ less than the working length. Intracanal calcium hydroxide dressing was placed and interim restoration was given. After 1 week, on the absence of pain, swelling, or discharge from the canal, obturation was done and root canal treatment was completed. One week postoperative review showed complete resolution of swelling and white eschar formation over the gingiva. Two weeks review showed absence of symptoms and soft-tissue healing at the site of incision in the muccobuccal region and pink healthy appearance of gingiva (Fig. 4). Postoperative review at

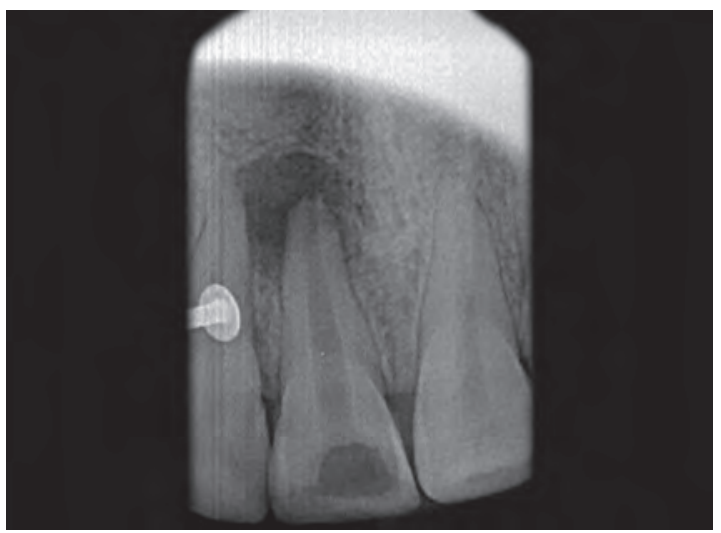

Fig. 2: Preoperative IOPA reveals periapical lesion in relation to 11,12 with periodontal widening

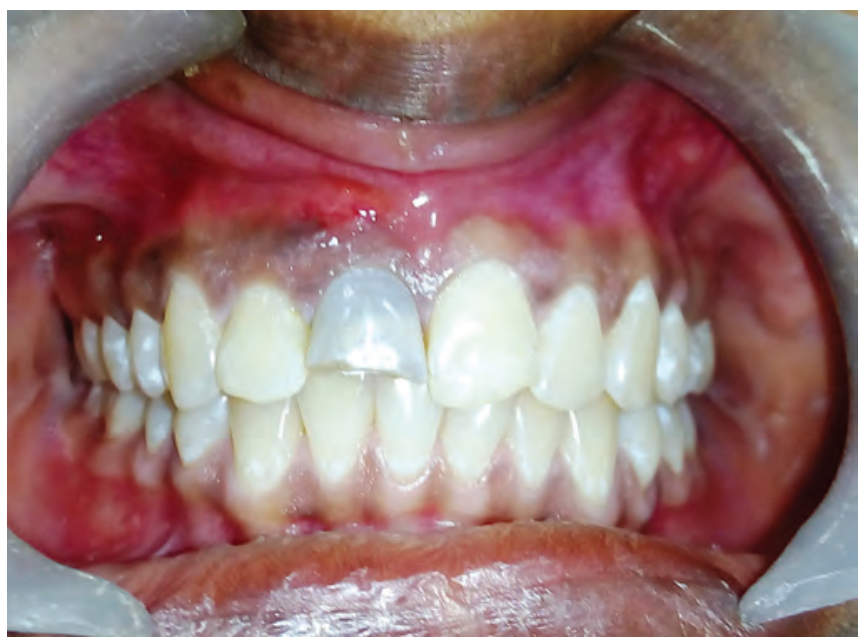

Fig. 4: Postoperative healing after successful root canal obturation in 11,12 


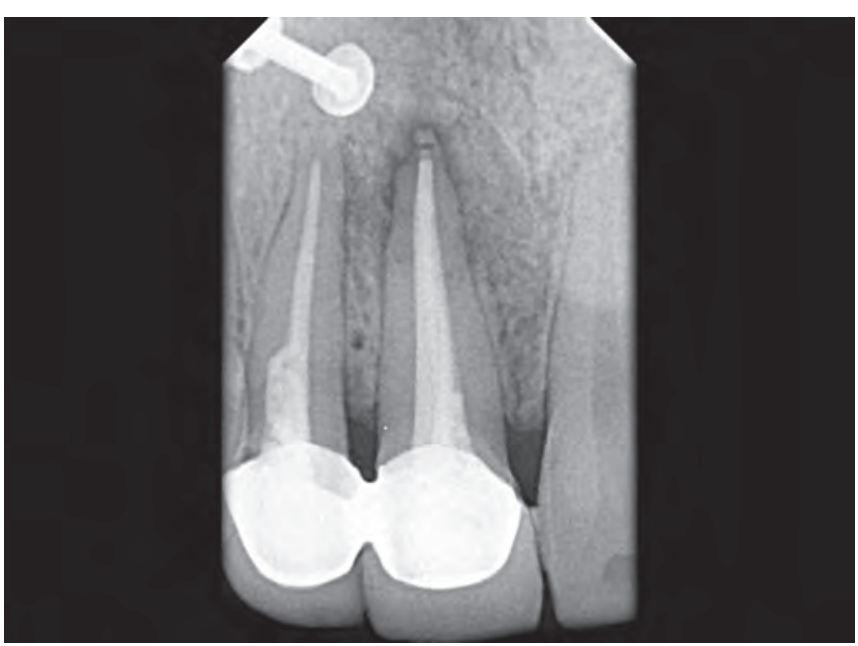

Fig. 5: One year postoperative IOPA of 11,12 reveals successful healing of the periapical lesion

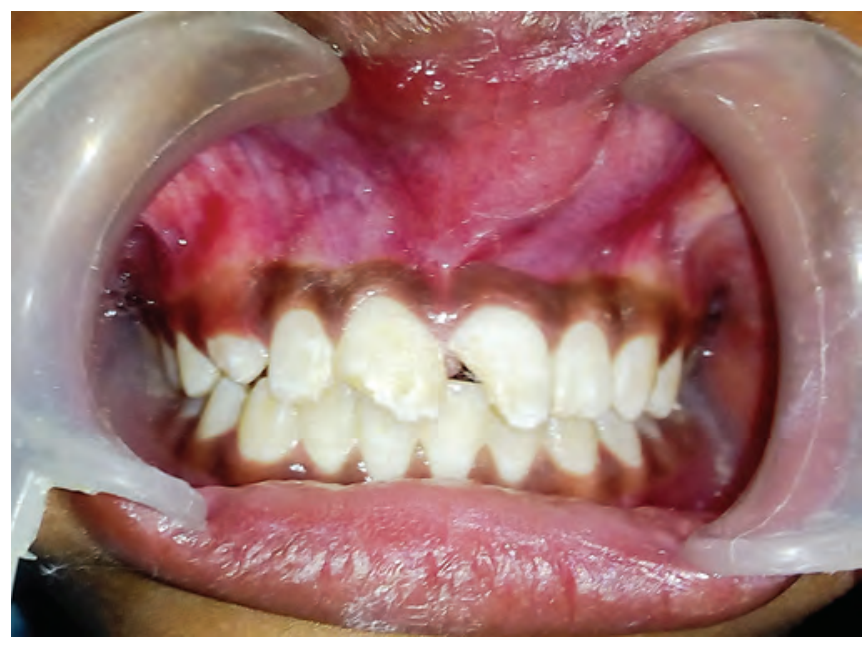

Fig. 6: Preoperative photograph of fractured 11, 12 with intraoral swelling in relation to periapical region of 21

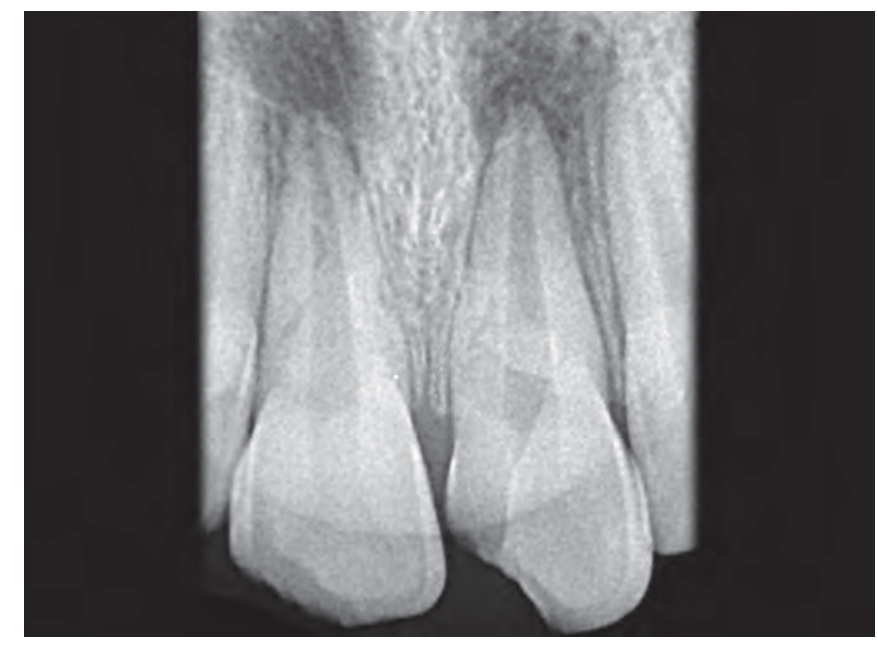

Fig. 7: Preoperative IOPA reveals diffuse radiolucency in relation to apical region of 11,21

week, the canals of 11, 21 was obturated and endodontic treatment was completed.

In the same sitting, new attachment procedure was done in 21 using $810 \mathrm{~nm}$ diode laser. The first step of lasing along the periodontal pocket begins from the gingival crest with $2 \mathrm{~mm}$ at a time, using $1 \mathrm{~W}$ continuous mode in " $Z$ " motion, with tip contacting the inner wall of the pocket. A second sitting of scaling was done at this point, concentrated at removing subgingival calculus (Fig. 8). The third step comprises again lasing the pocket to complete debridement, create a clot, and provide hemostasis (Fig. 9). The tissue is pressed firmly onto the tooth surface for 2 minutes to stabilize the clot.

It is important at this step to de-epithelialize the outer gingiva to delay epithelial overgrowth into the pocket. Patient was prescribed antibiotics, analgesics, and mouthwash. Two months review showed uneventful healing and absence of any symptoms (Fig. 10). Periodontal probing depth of $2 \mathrm{~mm}$ labially was recorded (Fig. 11). was given for 1 week. On resolution of symptoms after a 


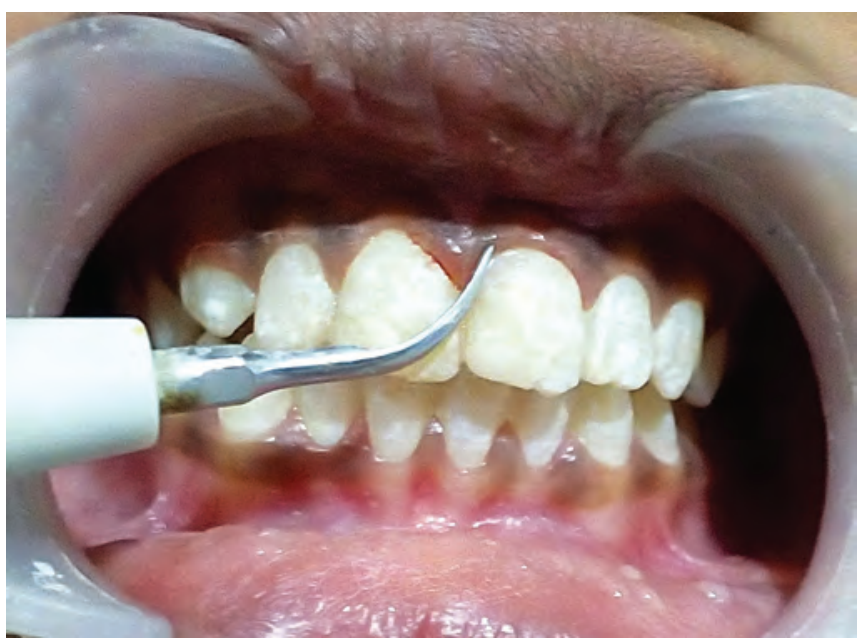

Fig. 8: Subgingival scaling was done

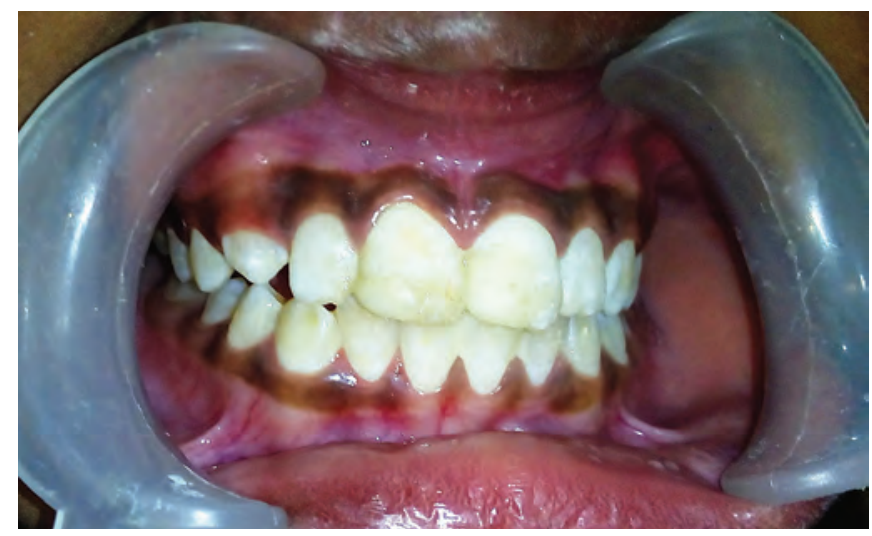

Fig. 10: Postoperative healing after laser treatment

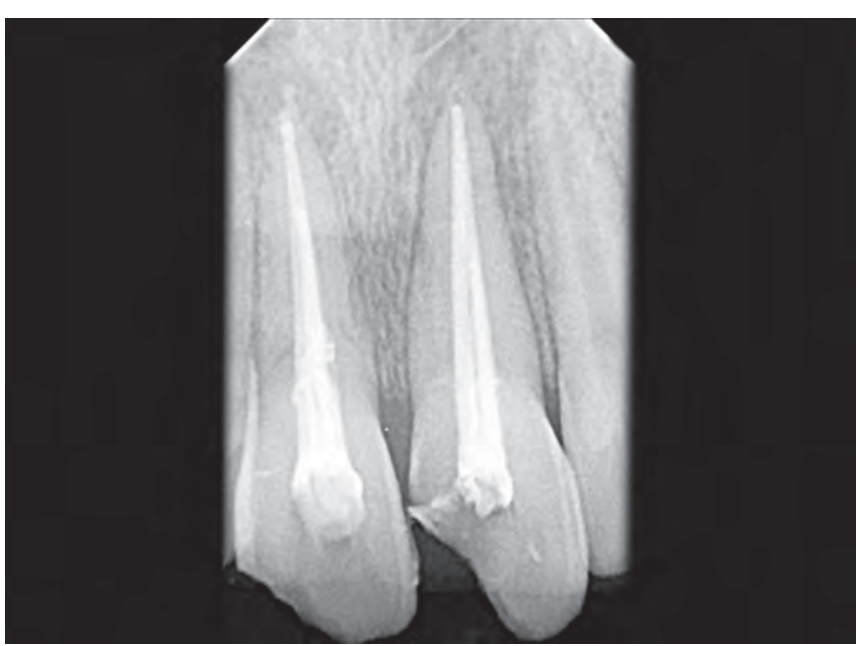

Fig. 12: Postoperative radiograph after 1 year

Composite restoration was done in 11, 21. Patient was reviewed after 1, 3, and 6 months. After 1 year, IOPA revealed reduction in periapical lesion and signs of healing, patient was asymptomatic with continuing gingival health (Fig. 12).

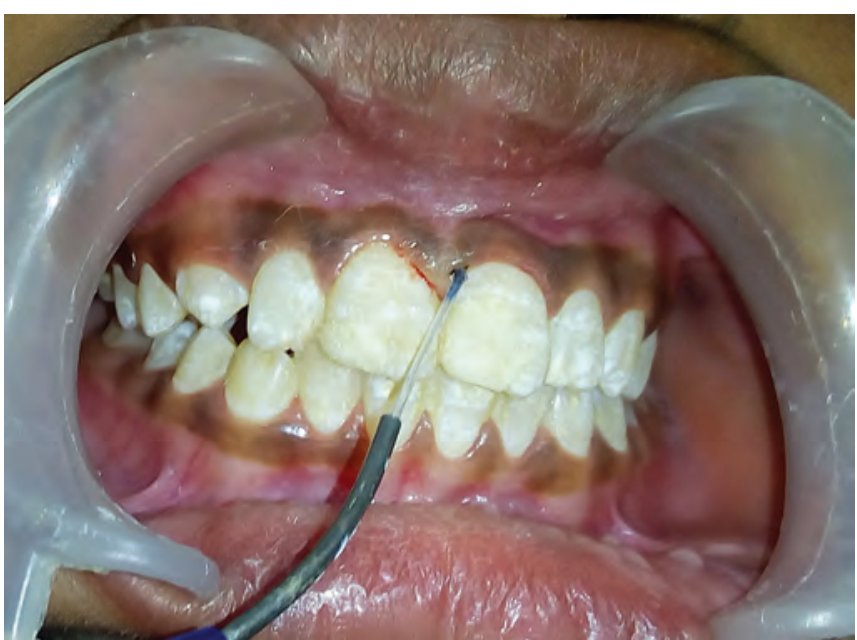

Fig. 9: Laser assisted new attachment procedure done in relation to 21 using diode laser

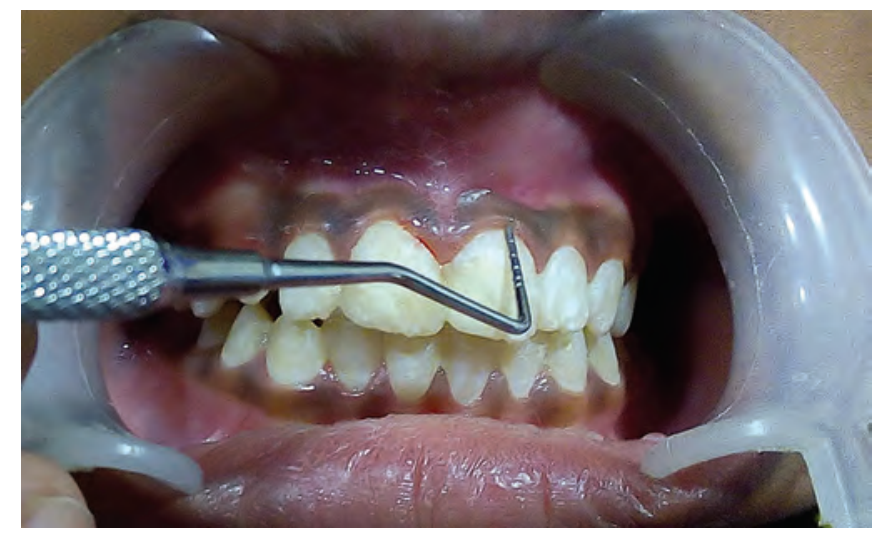

Fig. 11: Periodontal probing depth measured after 2 months period reduced to $3 \mathrm{~mm}$

\section{DISCUSSION}

The pulp and the periodontium share a close interrelationship owing to their embryonic development from a common mesodermal origin and complex anatomic connections. ${ }^{6}$ Thus the disease process in one tissue causes pathological changes in the other through three main pathways, namely through the apical foramen, dentinal tubules, and lateral canals. ${ }^{7}$

In the first case of true endodontic lesion, traumatic/ carious exposure of the pulp chamber either directly or through exposure from dentinal tubules caused pulpal inflammation by ingress of bacteria, which leads to build of pressure within the pulp canal and subsequent pulpal necrosis. ${ }^{8}$ As the periapical lesion expands, it causes perforation of cortical bone and drains into the gingival sulcus, forming a pseudopocket and periodontal involvement without causing any damage to the periodontal fibers as such. ${ }^{9}$ In such cases initiation of endodontic therapy has shown subsequent resolution of the periodontal involvement. 
Calcium hydroxide owing to its maintenance of alkaline $\mathrm{pH}$ in the canal is the preferred intracanal medicament to maintain antibacterial environment and aids in resolution of acute symptoms. ${ }^{10}$ The diode laser is assertively absorbed by the pigments in the bacterial cell wall. ${ }^{11}$ This inactivates the bacteria without decisively destroying them; nevertheless, it aids in the disinfection of the canal. In a study comparing the action of calcium hydroxide and laser, diode laser was found to be superior for disinfection of the root canal. ${ }^{12}$

The smear layer created by mechanical preparation of the canal harbors bacteria and its byproducts, which can delay or cause failure of endodontic treatment. ${ }^{13,14}$ Hence removal of smear layer and sealing of the dentinal tubules is an important goal in treating endodontic lesions. The use of conventional irrigants alone is insufficient owing to complexity of the root canal system. ${ }^{15,16}$ In vitro studies showed diode laser in combination with $3 \%$ sodium hypochlorite has proved to be a successful root canal disinfection regimen by combined smear layer removal and bacterial deactivation and sealing of apical dentinal tubules. Hence this regimen was used for canal disinfection. ${ }^{17}$

The primary effect of diode laser is photo thermal in nature, which is responsible for melting and sealing of dentinal tubules on exposure. ${ }^{18,19}$ Since diode is a straight firing laser, the eminent risk of using diode laser for root canal disinfection is due to collateral thermal damage to periapical tissue if used imprudently. Hence the fiberoptic tip is restricted to $1 \mathrm{~mm}$ short of the working length. The tip is never stationary within the canal; it is constantly moved so as to avoid raise in temperature of one particular portion of the canal. Previous studies have showed that reduction in exposure time is pivotal in preventing damage to surrounding tissue; hence short cycles of laser irradiation with ample resting time is an ideal regimen. ${ }^{20,21}$

In primary periodontal lesions, the pulp may be vital, which gives a clue to the origin of the disease. ${ }^{22}$ As discussed in the second case, periodontally involved teeth have been treated with a procedural approach named laser assisted new attachment procedure (LANAP). The main aim of this diode-aided periodontal therapy is gingival curettage. Previous studies have shown that scaling and root planing is not optional but definite form of treatment modality, and lasers are used only as adjuvants. ${ }^{23}$ Hence a combination of laser curettage and scaling with root planing was adopted to treat this patient. Laser assisted new attachment procedure has many advantages over conventional periodontal surgery, in which complication, such as attachment loss and recession of the gingiva and cratering result due to excessive tissue shrinkage. ${ }^{24,25}$ The diode laser due to its absorption in pigments as well as de-oxy hemoglobin is ideal to be used in gingival tissue. ${ }^{26,27}$ The use of laser for curettage of affected tissue increases visibility owing to its hemostatic property and also due to selective ablation of the sulcular epithelium. Moreover, lasers aid in deactivating the bacteria in the pockets and help in accelerating the healing process, which is impossible in conventional techniques. ${ }^{28,29}$ Adopting lasers for periodontal therapy in endo-perio lesions reduces chair side time for the dentist as endodontic and periodontic therapy can be performed in the same sittings. It also increases patient comfort with less postoperative pain, swelling, and absence for need of any dressings. 30,31

\section{CONCLUSION}

Application of lasers in endo-perio lesions is a promising and progressive treatment modality with increased benefits to both the clinician and patient. Nevertheless, the clinical application of laser does not supersede thorough diagnosis and treatment planning for endo-perio lesion. Further research with larger sample size of patients is recommended before developing a protocol for treatment of such lesions with diode lasers as adjuvant to regular therapy.

\section{REFERENCES}

1. Mathew S, Thangaraj DN. Lasers in endodontics. JIADS 2010 Jan-Mar;1(1).

2. Mjör IA, Nordahl I. The density and branching of dentinal tubules in human teeth. Arch Oral Biol 1996 May;41(5): 401-412.

3. Simring M, Goldberg M. The pulpal pocket approach: retrograde periodontitis. J Periodontol 1964 Jan-Feb;35(1):22-48.

4. Singh P. Endo-perio dilemma: a brief review. Dent Res J 2011 Winter;8(1):39-47.

5. Miserendino, L.; Pick, R.M. Lasers in dentistry. Quintessence Pub Co; 1995.

6. Mandel E, Machtou P, Torabinejad M. Clinical diagnosis and treatment of endodontic and periodontal lesions. Quintessence Int 1993 Feb;24(2):135-139.

7. Rotstein I, Simon JHS. Diagnosis, prognosis and decisionmaking in the treatment of combined periodontal-endodontic lesions. Periodontology 2000 2004;34(1):165-203.

8. Czarnecki RT, Schilder H. A histological evaluation of the human pulp in teeth with varying degrees of periodontal disease. J Endod 1979 Aug;5(8):242-253.

9. Soames, J.V.; Southam, J.C. Oral pathology. 3rd ed. Oxford: Oxford University Press; 1998.

10. Lacević A, Vranić E, Zulić I. Clinical application of calcium hydroxide in dental pathology and endodontics. Bosn J Basic Med Sci 2003 Nov;3(4):26-29.

11. Radvar M, Creanor SL, Gilmour WH, Payne AP, McGadey J, Foye RH, Whitters CJ, Kinane DF. An evaluation of the effects of an Nd:YAG laser on subgingival calculus, dentine and cementum. J Clin Periodontol 1995 Jan;22(1):71-77.

12. Ahmeduddin M, Nagesh B, Raj KS, Reddy KN. An assessment of bactericidal effect of two different types of lasers on enterococcus faecalis: an in vitro study. J Dent Lasers 2012 Sep;6(1):2-6. 
13. Fogel HM, Pashley DH. Dentin permeability: effects of endodontic procedures on root slabs. J Endod 1990 Sep;16(9): 442-445.

14. Gomes BP, Lilley JD, Drucker DB. Clinical significance of dental root canal microflora. J Dent 1996 Jan-Mar;24(1-2):47-55.

15. Gutknecht N, Franzen R, Schippers M, Lampert F. Bactericidal effect of a 980-nm diode laser in the root canal wall dentin of bovine teeth. J Clin Laser Med Surg 2004 Feb;22(1):9-13.

16. Gutknecht N. Lasers in endodontics. J Laser Health Acad 2008;4:1-4.

17. Kreisler M, Kohnen W, Beck M, Al Haj H, Christoffers AB, Gotz H, Duschner H, Jansen B, D'Hoedt B. Efficacy of NaOCI/ $\mathrm{H}_{2} \mathrm{O}_{2}$ irrigation and GaAlAs laser in decontamination of root canals in vitro. Lasers Surg Med 2003;32(3):189-196.

18. Da Costa Ribeiro A, Nogueira GE, Antoniazzi JH, Moritz A, Zezell DM. Effects of diode laser $(810 \mathrm{~nm})$ irradiation on root canal walls: thermographic and morphological studies. J Endod 2007 Mar;33(3):252-255.

19. Nandakumar A, Iyer VH. In vitro analysis comparing efficacy of lasers and desensitizing agents on dentin tubule occlusion: a scanning electron microscope study. Int J Laser Dent 2014 Jan-Apr;3(3):1-7.

20. Moritz A, Doertbudak O, Gutknecht N, Goharkhay K, Schoop U, Sperr W. Nd:YAG laser irradiation of infected root canals in combination with microbiological examinations. J Am Dent Assoc 1997 Nov;128(11):1525-1530.

21. Gutknecht N, Franzen R, Meister J, Vanweersch L, Mir M. Temperature evolution on human teeth root surface after diode laser assisted endodontic treatment. Lasers Med Sci 2005 Sep;20(2):99-103.

22. Simon JH, Glick DH, Frank AL. The relationship of endodontic-periodontic lesions. J Periodontol 1972 Apr;43(4):202-208.
23. Moritz A, Schoop U, Goharkhay K, Schauer P, Doertbudak O, Wernisch J, Sperr W. Treatment of periodontal pockets with a diode laser. Lasers Surg Med 1998;22(5):302-311.

24. Hill RW, Ramfjord SP, Morrison EC, Appleberry EA, Caffesse RG, Kerry GJ, Nissle RR. Four types of periodontal treatment compared over two years. J Periodontol 1981 Nov;52(11):655-662.

25. Johnson RE, Sigman JD, Funk GF, Robinson RA, Hoffman HT. Quantification of surgical margin shrinkage in the oral cavity. Head Neck 1997 Jul;19(4):281-286.

26. Stabholz A, Zeltser R, Sela M, Peretz B, Moshonov J, Ziskind D, Stabholz A. The use of lasers in dentistry: principles of operation and clinical applications. Compend Contin Educ Dent 2003 Dec;24(12):935-948.

27. The Academy of Laser Dentistry. Featured wavelength: diodethe diode laser in dentistry (Academy report). Wavelengths 2000;8:13.

28. Ben Hatit Y, Blum R, Severin C, Maquin M, Jabro MH. The effects of a pulsed Nd:YAG laser on subgingival bacterial flora and on cementum: an in vivo study. J Clin Laser Med Surg 1996 Jun;14(3):137-143.

29. Moritz A, Gutknecht N, DoertbudakO, Goharkhay K, SchoopU, Schauer P, Sperr W. Bacterial reduction in periodontal pockets through irradiation with a diode laser: a pilot study. J Clin Laser Med Surg 1997 Feb;15(1):33-37.

30. Kotlow L. Pediatric dentistry begins at birth: lasers and pediatric dental care in treating soft tissue lesions in the dental office. J Pediatr Dent Care 2007;13(1):12-16.

31. Pinheiro AL, Cavalcanti ET, Pinheiro TI, Alves MJ, Manzi CT. Low-level laser therapy in the management of disorders of themaxillofacial region. JClin LaserMedSurg 1997;15(4): 181-183. 
